In recent years surgical fashion has changed. At one time emergency surgery for haemorrhage from a duodenal ulcer implied a partial gastrectomy, but dissection and closure of the duodenal stump in these circumstances is often a difficult procedure, and increasingly often surgeons are carrying out the simple operation of pyloroplasty with underrunning of the ulcer under direct vision, supplemented by vagotomy. ${ }^{4}$ This change in surgical practice is reflected by the findings of Schiller and his colleagues. Over the last 15 years there was a switch away from gastrectomy to vagotomy combined with drainage. The consequence was a fall in operative mortality from $15 \%$ to $5 \%$. It is surprising, therefore, that no improvement in the overall fatality rate was observed in their series. This was found to be because a diminishing proportion of patients were treated by emergency surgery. Thus the improved results of operation were countered by the failure to perform emergency operations on as many patients at the end of the 15-years study as at the beginning. Clinicians should not be lulled by improved transfusion facilities and by more sophisticated diagnostic techniques from the well-established indications for urgent surgical intervention listed above.

What about the eventual prognosis of patients who have bled from duodenal ulcer in both the group treated conservatively and those submitted to surgery? R. F. Harvey and M. J. S. Langman ${ }^{6}$ report a 5-10-year follow-up in patients admitted to the Central Middlesex Hospital with bleeding duodenal ulcer. Of 278 patients in this study 211 were treated during the initial admission by conservative means and 67 were submitted to operation. In the medical treatment group $21 \%$ had subsequent recurrent bleeding or perforation compared with only $4.5 \%$ of those undergoing surgical treatment (all but 6 by Polya partial gastrectomy). A further 20 patients in the medically treated group underwent subsequent elective surgical operation compared with only 1 patient in the surgical group. The lower risk of recurrent haemorrhage or perforation in patients treated surgically than in those who received conservative treatment reinforces the conclusion of Schiller and his colleagues. Increasing caution in advising surgical operation for patients bleeding severely from a duodenal ulcer seems to be a retrograde step in both the immediate and the late prognosis.

1 Schiller, K. F. R., Truelove, S. C., and Williams, D. G., British Medical fournal, 1970, 2, 7.

2 Avery Jones, F., British Medical fournal, 1947, 2, 441 and 447.

3 Banning, A., Baron, A., Kopelman, H., Lam, K. L., and Warren, P., British Medical fournal, 1965, 2, 781.

4 Dorton, H. E., Annals of Surgery, 1961, 153, 378.

- Farris, J. M., and Smith, G. K., Annals of Surgery, 1960, 152, 416.

6 Harvey, R. F., and Langman, M. J. S., Quarterly fournal of Medicine, $1970,39,539$.

\section{Fibrous Dysplasia of Bone}

In their classic paper on hyperparathyroidism D. Hunter and H. M. Turnbull ${ }^{1}$ drew attention to a localized fibrous lesion of bone in which the rest of the skeleton is normal and which is never associated with abnormalities of calcium and phosphorus metabolism. They called this condition "focal osteitis fibrosa." L. Lichtenstein" ${ }^{2}$ coined the term "fibrous dysplasia" when reporting four patients with multiple bone lesions.
This interesting disease is unusual but not uncommon. Of unknown cause, it is probably developmental in origin. Primitive fibrous tissue proliferates in the medullary cavity and erodes the cortex from within, often producing expansion or distortion of the bone. The process may be localized to a small segment or may involve almost the entire bone. It may be monostotic or polyostotic. In the latter just one limb may be affected (monomelic) or a much wider area of the skeleton. It often shows a curious predilection for one side only. In the polyostotic disease some patients-nearly always femalesshow a remarkable combination of skin pigmentation and endocrine disturbances such as precocious puberty or hyperthyroidism (Albright's syndrome). ${ }^{3}$

The femur and tibia are most commonly affected. The monostotic form is by far the commoner and is usually clinically silent until a pathological fracture occurs. Pain and swelling draw attention to lesions in the skull and jaw, while the disease in the rib cage or pelvis is often discovered incidentally on radiological examination for some other condition. The commonest age of presentation in the long bones is in adolescence and in the jaws in early adult life. Rib lesions may be discovered at any age. The polyostotic cases may present with endocrine dysfunction-for example, vaginal bleeding at three years of age ${ }^{4}-$ or because of progressive deformity when the skeleton is widely affected.

Firm diagnosis of the monostotic lesion requires biopsy. Radiologically it may closely resemble many other benign lesions of bone, such as simple cyst, non-ossifying fibroma, and enchondroma. In the jaws dental cyst or adamantinoma must be considered. When the disease affects several bones the radiographic appearances are usually sufficiently characteristic to warrant a firm diagnosis being made without the aid of the morbid anatomist. M. J. Gibson and J. H. Middlemiss ${ }^{5}$ recently gave a full description of the radiographic appearances of both the monostotic and polyostotic forms of the disease and suggested that the term "fibrous dysplasia" may include several conditions closely related histologically but not in fact one pathological entity.

The proliferation of fibrous tissue usually ceases at skeletal maturity, but not always. Some lesions are reactivated in adult life-for example, in pregnancy. Sarcomatous degeneration has been reported in fibrous dysplasia but is rare. However, because of this, irradiation of the benign lesion should be avoided, as it may lead to malignant change later on. ${ }^{8}$ Gross deformity can occur in the polyostotic disease when the lower limbs are widely affected. Characteristically the femoral neck and proximal shaft bend into a "shepherd's crook." The mid-shaft of the femur assumes an exaggeration of the normal anterior and lateral bowing. The tibia bows inwards. These deformities predispose to pathological fracture owing to their poor resistance to the forces involved in weight bearing. Fractures of the neck and upper femoral shaft are almost certain if the deformity is allowed to persist.

Treatment is directed towards the skeletal manifestations. Fractures through dysplastic bone unite readily: the problem is to prevent further failure through the weakened area by eradicating the diseased tissue. This is sometimes difficult. Simple curettage and bone grafting does not invariably succeed, and more drastic measures such as en bloc excision may be required. ${ }^{9}$ Correction, or preferably prevention, of deformity requires osteotomy, with the addition of adequate internal fixation to strengthen the weakened bone.

Fibrous dysplasia can involve tissues of both mesodermal and ectodermal origin. The term may in fact cover a range of closely related but distinct lesions. There is however, 
ample scope for the surgical relief of disability in these patients with "fibrous dysplasia". 1 Hunter, D., and Turnbull, H. M., British fournal of Surgery, 1931, 19,

2 Lichtenstein, L., Archives of Surgery, 1938, 36, 874.

3 Albright, F., Butler, A. M., Hampton, A. O., and Smith, P., New England Fournal of Medicine, 1937, 216, 727.

4 Falconer, M. A., and Cope, C. L., Quarterly fournal of Medicine, 1942, $11,121$.

5 Gibson, M. J., and Middlemiss, J. H., British fournal of Radiology, 1971, 44,1 .

- Dockerty, M. B., Ghormley, R. K., Kennedy, R. L. J., and Pugh, D. G., Archives of Internal Medicine, 1945, 75, 357.

7 Henry, A. N., M.Ch. Thesis, University of Dublin, 1963, 87.

8 Harris, W. H., Dudley, H. R., and Barry, R. J., Fournal of Bone and foint Surgery, 1962, 44-A, 207.

- Henry, A., Fournal of Bone and Foint Surgery, 1969, 51-B, 300.

\section{The Pill and Folate Metabolism}

It looks as though an action on folate metabolism must now be added to the long list of effects of oral contraceptives. While they are certainly no cause for alarm, the observations raise interesting questions about the way in which dietary folate is utilized. A. M. Shojania and his colleagues ${ }^{1}{ }^{2}$ found that women taking oral contraceptives had a lower average concentration of folate in the serum and red cells and a higher figlu excretion in the urine than control persons. These early observations were not confirmed by others, ${ }^{3}{ }^{4}$ and it seems likely that the majority of women on the pill can absorb sufficient folate from their food to avoid becoming deficient. Nevertheless there have been a handful of reports of megaloblastic anaemia. ${ }^{5} 6$ Of the seven patients described by R. R. Streiff ${ }^{5}$ five responded satisfactorily to daily doses of $250 \mu \mathrm{g}$ folic acid while still taking oral contraceptives and two had a reticulocyte response when the contraceptives were discontinued. When absorption tests were carried out in women on the pill ${ }^{5}$ it was found that folic acid (monoglutamate) was utilized normally, while serum folate levels fell by as much as $50 \%$ after ingestion of folic polyglutamates, the form in which dietary folate is present.

Folic polyglutamates in the diet are broken down by a conjugase enzyme in the small intestine to the monoglutamate (folic acid), which is then absorbed, though it is uncertain whether this action occurs in the lumen of the gut or in the mucosa. The anticonvulsant, phenytoin, appears to inhibit conjugase activity in vitro, ${ }^{8} 9$ but few epileptic patients taking the drug develop megaloblastic anaemia or even folate deficiency, and individuals must vary considerably in their sensitivity and ability to utilize dietary folate. The similarity between this situation and that of women on the pill or during pregnancy is striking, but it has not yet been established whether conjugase inhibition occurs in these latter two circumstances. It would be tempting also to assume that the tendency to folate deficiency in pregnancy is related to the inhibition of folic polyglutamate absorption that occurs in women on the pill, but a recent study ${ }^{10}$ showed no difference in absorption of mono- and polyglutamates by women in the latter half of pregnancy. More work on these lines is needed together with tests of conjugase activity similar to those involving phenytoin, not only to see if there is conjugase inhibition but also to determine which of the steroid hormones or their metabolites inhibit the absorption of polyglutamates. Such observaticns may eventually solve the riddle of folate deficiency in pregnancy.

In the meantime it must be stressed that cral contraceptives are an unusual cause of megaloblastic anaemia and that malnutrition, malabsorption, liver damage, and perhaps pregnancy itself are more likely. Even in women taking oral contraceptives these causes should be excluded. Provided this is done, an adequate dietary intake plus $250 \mu \mathrm{g}$ folic acid daily should be sufficient to maintain the health of the few susceptible individuals who wish to continue taking the pill.

1 Shojania, A. M., Hornady, G., and Barnes, P. H., Lancet, 1968, 1, 1376. 2 Shojania, A. M., Hornady, G., and Barnes, P. H., Lancet, 1969, 1, 886. Spray, G. H., Lancet, 1968, 2, 110.

McLean, F. W., Heine, M. W., Held, B., and Streiff, R. R., American Journal of Obstetrics and Gynecology, 1969, 104, 745.

Streiff, R. R., Fournal of the American Medical Association, 1970, 214, 105. Paton, A., Lancet, 1969, 1, 418.

Necheles, T. F., and Snyder, L. M., New England fournal of Medicine, $1970,282,858$

${ }^{8}$ Hoffbrand, A. V., and Necheles, T. F., Lancet, 1968, 2, 528.

${ }^{9}$ Rosenberg, I. H., Godwin, H. A., Streiff, R. R., and Castle, W. B., Lancet, 1968, 2, 530.

10 McLean, F. W., Heine, M. W., Held, B., and Streiff, R. R., Blood, 1970, 36,628 .

\section{Polio Risks}

The routine use of live oral poliovirus vaccine on a mass scale began in a number of countries in the spring of 1960 . It followed three years of thorough international collaborative studies. These had proceeded step by step from an initial clinical trial in a few volunteers to extensive field evaluation on millions of people. The studies showed that the Sabin strains of attenuated virus provided a high level of protection without producing harmful effects and that, though the virus could spread from vaccinated persons to household contacts, the transmitted infection also was harmless but immunizing. Since 1960 more than two thousand million people have received the vaccine, but even to-day vaccination presents problems, some of which are only just emerging. Paradoxically, the two main ones are the poor performance of the vaccine in tropical countries and the repercussions of its sheer efficacy in the temperate zone.

In tropical countries a high proportion of infants and young children are subject to a seemingly endless succession of intestinal infections, which can prevent the live vaccine from establishing itself in the intestines, a prerequisite to the development of immunity. In view of this and the difficulties in carrying out mass vaccination programmes it is not surprising that most tropical countries reported a few hundred new cases of paralytic poliomyelitis during 1969, whereas very few in the temperate zone had as many as 15 cases. ${ }^{1}$

In temperate countries mass vaccination programmes sustained over a period of a few years have rendered paralytic poliomyelitis a rare disease. The public feel increasingly secure from the disease and consequently are losing interest in vaccination. The introduction of new immunization schedules in Britain failed to halt the decline in infant vaccination rates, and it seems that further exhortation of defaulting mothers will have little effect on this trend. Few parents withhold their consent to the vaccination of school children, and the offer of vaccine to school entrants, as recommended in this country, 